\title{
MONTAGEM DE COLEÇÃO DE CORAÇÕES CRIODESIDRATADOS DE ANIMAIS DOMÉSTICOS
}

Assembling a collection of freeze-dried domestic animal hearts

Montaje de la coleccíon corazones de animals domésticos liofilizados

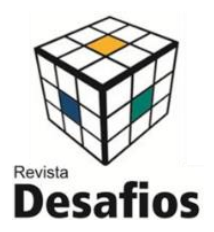

\author{
Raissa Menêses da Silva de Miranda ${ }^{1}$, Andréa Cristina Scarpa Bosso ${ }^{2}$ \\ ${ }^{1}$ Aluna do curso de Medicina Veterinária, Universidade Federal do Tocantins, Araguaína, \\ Brasil.
}

${ }^{2}$ Orientadora do curso de Medicina Veterinária, Universidade Federal do Tocantins, Araguaína, Brasil.

Artigo recebido em 30/03/2020 aprovado em 28/05/2020 publicado em 30/10/2020.

\section{RESUMO}

A utilização de técnicas de conservação de materiais para estudo anatômico auxilia na didática das aulas e na transmissão do conhecimento anatômico, além de prolongar o tempo de uso de peças frescas e protegê-los de microrganismos deteriorantes inerentes aos cadáveres. Dentre diversas técnicas de conservação está o processo de criodesidratação, que, com o uso de formaldeído e posterior exposição das peças a sucessivos congelamentos e descongelamentos, torna-as, duráveis e leves. Nesse trabalho empregou-se a técnica de criodesidratação descrita por TEIXEIRA, et al. (1990) e TEIXEIRA FILHO, et al. (1996) em corações de diferentes espécies. O objetivo desse projeto foi testar essa técnica e a ampliação da coleção do Laboratório de Anatomia Animal da EMVZ/UFT - Campus Araguaína, com elementos anatômicos facilmente acondicionáveis, com grande durabilidade e, principalmente, a baixo custo. Acompanhou-se a perda de massa de cada peça nas diferentes etapas do processo e, ao final do processo, a média final de desidratação coincidiu com valores médios propostos pela literatura. O material produzido por esse estudo ficará disponível no laboratório de Anatomia Animal da EMVZ/UFT a disposição dos alunos e professores, servindo como subsídio para o ensino das disciplinas de ciências morfológicas, de técnicas cirúrgicas e projetos de extensão universitária.

Palavras-chave: Coleção, Anatomia, Técnica Anatômica.

\section{ABSTRACT}

The use of material conservation techniques of hearts for anatomical study helps in the didactics of classes. Also, the transmission of anatomical knowledge and prolonging the use of fresh heart pieces protecting them from deteriorating microorganisms that are inherent in cadavers. Among several conservation techniques is the freezedrying process, which, with the use of formaldehyde and subsequent exposure of the pieces to successive freezing and thawing makes them durable and light. In this work was used from freeze-drying technique described by TEIXEIRA, et al. (1990) and TEIXEIRA FILHO, et al. (1996) in hearts of different species. The scope of this project is to test this technique and expand the collection of the Animal Anatomy Laboratory of EMVZ/UFT - Campus Araguaina, with anatomical elements, easily packaged, with great durability and, especially, at low cost. It was accompanied by the mass loss of each piece in the different stages of the process, and at the end stage, the dehydration average coincided with average values proposed by the literacture. The material produced by this study is available at the Animal Anatomy laboratory of EMVZ/UFT at the disposal of students and professors, serving as a subsidy for the teaching of the disciplines of Morphological Sciences, Surgical Techniques and university extension projects.

Keywords: Collection, Anatomy, Anatomical Technique.

\section{RESUMEN}

El uso de técnicas de conservación de materiales para el estudio anatómico ayuda en la didáctica de las clases y en la transmisión del conocimiento anatómico, además de prolongar el uso de piezas frescas y protegerlas del deterioro de los microorganismos inherentes a los cadáveres. Entre varias técnicas de conservación se encuentra el proceso de criodeshidratación, que, con el uso de formaldehído y la posterior exposición de las piezas a sucesivas 
congelaciones y descongelaciones, las hace duraderas y livianas. En este trabajo, la técnica de criodeshidratación descrita por TEIXEIRA, et al. (1990) y TEIXEIRA FILHO, et al. (1996) en corazones de diferentes especies. El objetivo de este proyecto es probar esta técnica y la ampliar la colección del Laboratorio de Anatomía Animal de EMVZ/UFT - Campus Araguaína, con elementos anatómicos fácilmente empaquetables, con gran durabilidad y, especialmente, a bajo costo. La pérdida de masa de cada parte se monitoreó en las diferentes etapas del proceso y, al final del proceso, el promedio de deshidratación final coincidió con los valores promedio propuestos por la literatura.. El material producido por este estudio está disponible en el Laboratorio de Anatomía Animal de EMVZUFT a disposición de estudiantes y profesores, sirviendo como subsidio para la enseñanza de las disciplinas de Ciencias Morfológicas, Técnicas Quirúrgicas y proyectos de extensión universitaria.

Descriptores: Colección, Anatomía, Técnica anatómica.

\section{INTRODUÇÃO}

Atualmente empregam-se diversas técnicas para conservação de determinadas estruturas, com a finalidade de preservar a forma, cor, aparência, dimensões e relações dos órgãos para posterior estudo, possibilitando ao observador, acadêmico ou profissional, explorar e visualizar a forma do mesmo órgão de diferentes maneiras (RODRIGUES, 2010; BALTA et al., 2015).

A técnica de desidratação de músculos desenvolvida por TEIXEIRA, et al. (1990) e técnica da criodesidratação aplicada em vísceras ocas e parenquimatosas realizada por TEIXEIRA, et al. (1996), são ideais para a produção de peças para compor coleção de museus biológicos, para se manter em consultórios, a fim de ilustrar explanações de condutas ao proprietário ou mesmo para fins didáticos. Ela promove a obtenção de material facilmente condicionável, com perda de peso em torno de $60 \%$, com grande durabilidade e, principalmente, de baixo custo.

Os autores, baseados nos procedimentos adotados em frigoríficos para conservação de carcaças pelo frio, realizaram sucessivos congelamentos (aproximadamente até $-17^{\circ} \mathrm{C}$ ) e descongelamentos. $\mathrm{O}$ congelamento da água no interior da célula causa sua expansão e formação de cristais de gelo, grandes o suficiente para romper a membrana plasmática celular e o afastamento das fibras musculares; já o descongelamento facilita a liberação de água do tecido, promovendo a retirada de líquidos dos tecidos e consequente desidratação do material. Através de repetições desse procedimento um número maior de rupturas acontece na parede celular e mais desidratada a peça se torna.

CURY e colaboradores (2013) descreveram que as peças criodesidratadas tornaram-se sólidas, rígidas e muito leves, tanto em órgãos separados quanto a animais inteiros posicionados in situ. Também observaram que fazer a criodesidratação em órgãos já fixados e conservados em formol as tornaram completamente inodoras.

Dentre as descritas na literatura, são vantagens descritas do método de criodesidratação de vísceras ocas a eliminação do uso de fixadores nocivos à saúde, facilidade no condicionamento da peça, a redução do peso, pouco gasto com conservantes para preparar e manter as peças, permitir dissecações e explorações mesmo depois de desidratadas (KREMER et al., 2011; CURY et al., 2013).

Dessa forma, esse projeto se justifica pela importância das coleções didáticas permanentes de fácil manutenção no Laboratório de Anatomia Veterinária da Universidade Federal do Tocantins, Campus Araguaína, com pronta utilização em estudos de aspectos anatômicos e comparativos macroscópicos das diversas espécies domésticas, que podem ser empregadas em atividades de ensino, pesquisa e extensão, essas peças teriam papel enriquecedor junto à comunidade local. 


\section{MATERIAIS E MÉTODOS}

Para iniciar a técnica de criodesidratação segundo técnica descrita por TEIXEIRA, et al. (1990) e TEIXEIRA et al. (1996) e adaptada por KREMER et al. (2011), foram coletados corações de várias espécies Os corações foram adequadamente identificados e colocados no freezer para conservação. Em momento apropriado as peças foram descongeladas, realizou-se uma dissecação grosseira do material, lavagem, pesagem e suas imagens capturadas com auxílio de câmera digital.

Em momento apropriado, as peças foram injetadas e posteriormente totalmente imersas em solução de formol a $10 \%$ e ali permaneceram para fixação por período de aproximado de 15 dias, variando com o tamanho da peça. Após esse período, as peças foram lavadas em água corrente e feitas à segunda dissecação e pesagem.

Figura 1: Pesagem das peças anatômicas criodesidratadas. Em A, pesagem do coração de boi (peça aberta); em B, pesagem do coração de mula; em C, pesagem do coração de gato (peça aberta); em D, pesagem do coração de gato; em E, pesagem do coração de cadela; em F, pesagem do coração de cão; em G, pesagem do coração de cão; em H, pesagem do coração de cão (peça aberta); em I, pesagem do coração de cavalo (peça aberta).

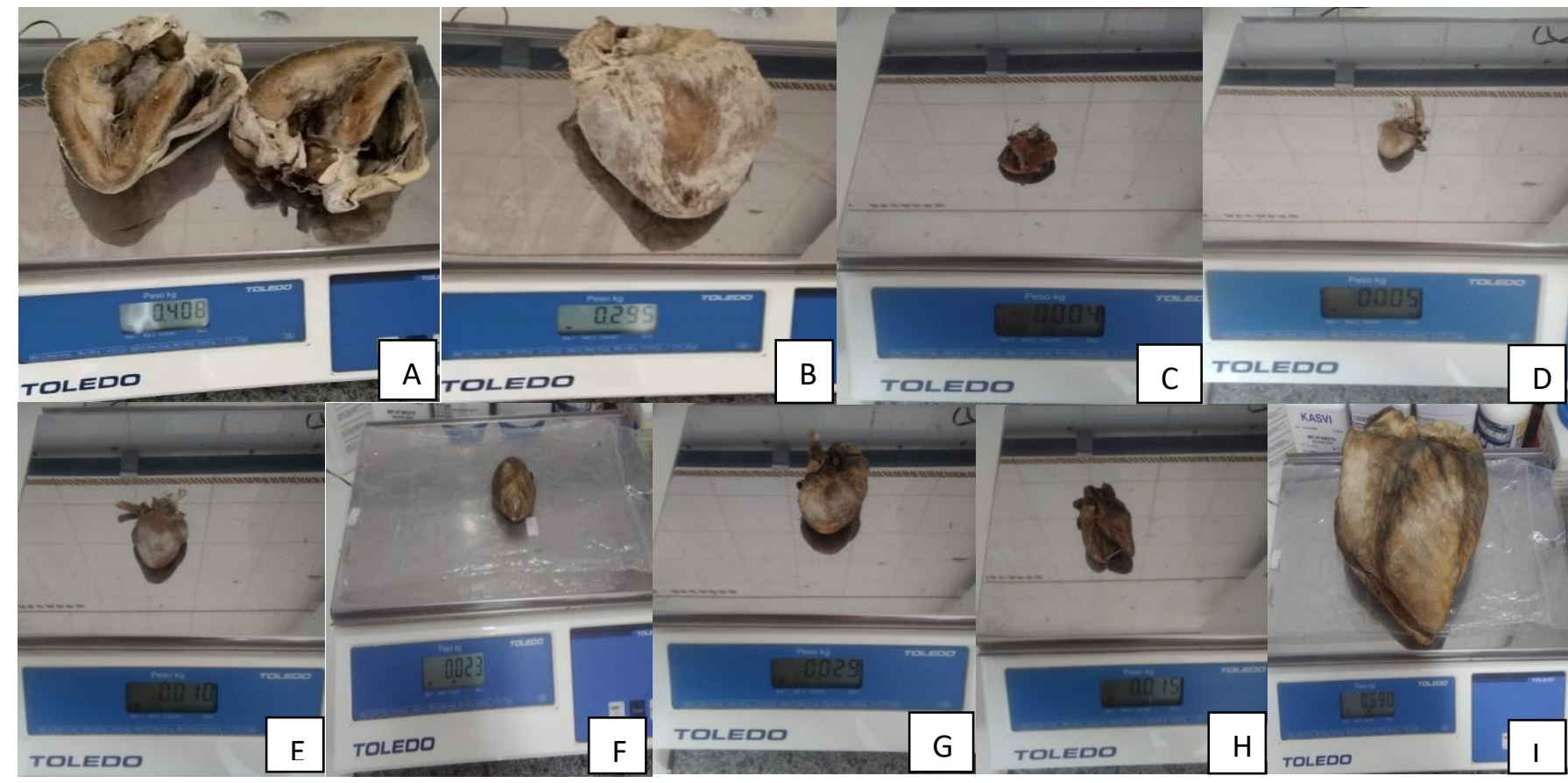

Os pesos individuais de cada peça foram anotados em planilha específica e realizadas antes, durante e depois da técnica de criodesidratação, concordando ou discordando com dos valores médios comparações estatísticas simples entre perda de peso 
de $60 \%$ de perda de peso descritos por TEIXEIRA et al. (1996).

\section{RESULTADOS E DISCUSSÃO}

Segundo BALTA e colaboradores (2015), estudos morfológicos requerem a preservação das partes do corpo, tanto para permitir investigações anatômicas por períodos prolongados àqueles que cadáveres frescos permitiriam, por causa de sua decomposição natural, como também para proteger os estudantes e docentes de agentes infecciosos inerentes aos cadáveres. Dessa forma, esse estudo realizou uma forma diferente de preservação de corações de animais domésticos no Laboratório de Anatomia Animal da EMVZ/ UFT, testando a técnica descrita por TEIXEIRA, et al. (1990) e TEIXEIRA et al. (1996) e adaptada por KREMER et al. (2011).

Durante o período do projeto foram feitas revisões bibliográficas, onde se observou escassez de publicações recentes sobre essa técnica de criodesidratação para obtenção de peças anatômicas. A mais recente foi a breve revisão da técnica por CARMO E MARTINS (2016), incluindo os mesmos autores aqui citados. No entanto, no que tange as ciências morfológicas básicas, o uso de literatura antiga não interferiu nos resultados presentes, fato confirmado por esse trabalho.

Dessa forma, o uso da técnica de criodesidratação nesse estudo confirmou a importância e a eficácia da técnica por promover melhorias no manuseio das peças, que ficam mais leves, inodoras, rígidas, com longa duração, facilidade de conservação e com o custo relativamente baixo. Assim, as autoras confirmam ser bastante viável para confecção de corações criodesidratados para aplicação em aulas práticas, palestras, semanas de divulgação de ciência e diversos outros estudos morfológicos.

$\mathrm{Na}$ Tabela 1 estão às massas dos corações de cada espécie em cada etapa do processo, as médias e desvio padrão desses dados, para comparação com a literatura. Dessa forma, obtivemos uma media de $62 \%$ de perda de massa em relação às peças frescas, sendo como valor máximo $76 \%$ e mínimo $60 \%$, o que corresponde com KREMER, et al. (2011) e TEIXEIRA, et al. (1996).

Tabela 1. Letra de identificação das peças anatômicas coletadas, animal doméstico a qual elas eram originárias, massa em quilogramas da peça fresca, formolizada e criodesidratada; perda de massa após processos de formolização e criodesidratação; porcentagem de perda de massa após processos de formolização e criodesidratação; descrição de média e desvio padrão dos valores obtidos.

\begin{tabular}{|c|c|c|c|c|c|c|c|c|}
\hline \multirow{2}{*}{$\begin{array}{c}\text { Identificação } \\
\text { das peças } \\
\text { anatômicas }\end{array}$} & \multirow[t]{2}{*}{$\begin{array}{c}\text { Animal } \\
\text { doméstico }\end{array}$} & \multirow{2}{*}{$\begin{array}{c}\text { Peça } \\
\text { fresca } \\
(\mathbf{k g})\end{array}$} & \multirow{2}{*}{$\begin{array}{c}\text { Peça } \\
\text { formoli- } \\
\text { zada (kg) }\end{array}$} & \multirow{2}{*}{$\begin{array}{c}\text { Peça } \\
\text { criodesidra- } \\
\text { tada (kg) }\end{array}$} & \multicolumn{2}{|c|}{ Perda de massa } & \multicolumn{2}{|c|}{$\begin{array}{l}\text { Porcentagem de } \\
\text { perda de massa }\end{array}$} \\
\hline & & & & & $\begin{array}{c}\text { For- } \\
\text { mo- } \\
\text { lização }\end{array}$ & $\begin{array}{c}\text { Crio- } \\
\text { desi- } \\
\text { dratação }\end{array}$ & $\begin{array}{l}\text { Formo- } \\
\text { lização }\end{array}$ & $\begin{array}{l}\text { Criodesi- } \\
\text { dratação }\end{array}$ \\
\hline $\mathbf{A}$ & Boi & 1,513 & 1,378 & 0,408 & 0,135 & 1,105 & $9 \%$ & $73 \%$ \\
\hline B & Mula & 1,069 & 0,996 & 0,295 & 0,073 & 0,774 & $7 \%$ & $72 \%$ \\
\hline $\mathbf{C}$ & Gato & 0,012 & 0,012 & 0,004 & 0 & 0,008 & $0 \%$ & $67 \%$ \\
\hline D & Gato & 0,017 & 0,016 & 0,005 & 0,001 & 0,012 & $6 \%$ & $71 \%$ \\
\hline $\mathbf{E}$ & Cão & 0,076 & 0,072 & 0,029 & 0,004 & 0,047 & $5 \%$ & $62 \%$ \\
\hline $\mathbf{F}$ & Cão & 0,086 & 0,085 & 0,023 & 0,001 & 0,063 & $1 \%$ & $73 \%$ \\
\hline $\mathbf{G}$ & Cão & 0,041 & 0,037 & 0,01 & 0,004 & 0,031 & $10 \%$ & $76 \%$ \\
\hline $\mathbf{H}$ & Cão & 0,044 & 0,042 & 0,015 & 0,002 & 0,029 & $5 \%$ & $66 \%$ \\
\hline
\end{tabular}




\begin{tabular}{|c|c|c|c|c|c|c|c|}
\hline Cavalo & 1,744 & 1,706 & 0,69 & 0,038 & 1,054 & $2 \%$ & $60 \%$ \\
\hline Média & 0,076 & 0,072 & 0,023 & 0,004 & 0,047 & $5 \%$ & $62 \%$ \\
\hline Desvio padrão & 0,719 & 0,681 & 0,247 & 0,046 & 0,481 & $3 \%$ & $5 \%$ \\
\hline
\end{tabular}

Concordando com TEIXEIRA, et al. (1996 e 1991) essa técnica para preparo de corações de mamíferos domésticos é de fácil exequibilidade, baixo custo e oferece vantagens de acondicionamento, transporte e manutenção em relação as demais técnicas tradicionais de fixação e manutenção das peças anatômicas.

\section{CONCLUSÃO}

Foi possível realizar a coleta de nove corações de animais domésticos, seu congelamento, pesagem a fresco e fixada em formol a $10 \%$, e técnica de criodesidratação segundo TEIXEIRA, et al. (1996) para o Laboratório de Anatomia da Universidade Federal do Tocantins, Campus Araguaína.

Ao final desta técnica, os corações apresentaram média de $62 \%$ a menos do seu peso inicial, concordando com os mesmos autores supracitados. Notou-se, como vantagens, a fácil manipulação das peças anatômicas desse estudo, além de baixo odor residual e baixo custo do preparo.

\section{AGRADECIMENTO}

Meus sinceros agradecimentos à professora Andréa Cristina Scarpa Bosso, pois este projeto não teria como ser realizado sem a excepcional orientação, colaboração e apoio da mesma que dedicou toda a sua atenção para ajudar-me em cada processo da técnica de criodesidratação em corações de diferentes espécies, passando-me todo o seu conhecimento sobre a técnica em questão e dando-me liberdade para confeccionar as peças da forma que fosse mais adequada a meu ver e que trouxesse benefícios para estudos anatômicos. Agradeço também a técnica do Laboratório de Anatomia Animal da UFT, Helane Tavares que se disponibilizou a auxiliar-me com a fixação das peças no formol e no que fosse necessário.

Todos os autores declararam não haver qualquer potencial conflito de interesses referente a este artigo.

\section{REFERÊNCIAS}

BALTA, J. Y.; CRONIN, M.; CRYAN, J. F.; O'MAHONY, S. Human preservation techniques in Anatomy: a 21st century medical education perspective. Clinical Anatomy. N. 28, p. 725-734, 2015.

CARMO, L. G.; MARTINS, L. L. Técnica de criodesidratação em vísceras para o estudo da anatomia animal. I Simpósio em Produção Sustentável e Saúde Animal - PPS. Umuarama, março, 2016.

CURY, F. S.; CENSONI, J. B.; AMBROSIO, C. E. Técnicas anatômicas no ensino da p2016rática de anatomia animal. Pesquisa Veterinária Brasileira. n.33, v. 5, p. 688-696, maio, 2013.

KREMER, R.; SCHUBERT, J. M. BONFÍLIO, N. S. Criodesidratação de vísceras do canal alimentar no preparo de peças anatômicas para estudo veterinário. Pubvet. Londrina, v. 5, n. 13, ed. 160, art. 1081, 2011. RODRIGUES, H. Técnicas Anatômicas. 4. ed. Vitória: GM Editora, 2010.

TEIXEIRA, A. F.; GUARENTI, V.P.J.; TEIXEIRA, A.; CARAMBULA, S. F.; CRUZATI, A.; BRUCKER, P.F. The cryodehydration technique applied to cavitary and parenchymatous viscera. Brazilian Journal of Morphogical Science, v.13, n.2. p. 177-180, 1996.

TEIXEIRA, A.; TEIXEIRA, A. F.; GUARENTI, V. P. J. Desidratação de músculos no preparo de peças anatômicas. Revista Brasileira de Ciências Morfológicas, v. 7/8, n.2/1, p.45-7, 1990-1991. 